\title{
Prospects for the development of green and energy efficient technologies in construction
}

\author{
Arkadiy Larionov 1,*, Ludmila Metechko², Artem Davydov ${ }^{3}$ and Denis Davydov ${ }^{3}$ \\ ${ }^{1}$ Moscow State University of Civil Engineering, Yaroslavskoe sh., 26, 129337, Moscow, Russia \\ ${ }^{2}$ Moscow Aviation Institute, Volokolamskoe highway, 4, 125993, Moscow, Russia \\ ${ }^{3}$ Plekhanov Russian University of Economics, Stremyanny lane, 36, 117997, Moscow, Russia
}

\begin{abstract}
Energy saving technologies have recently been considered at the level of state and international policy. Various opinions on the causes of appreciation of energy resources, on depletion of natural resources, changes in climate and many other problems are coming from the expert community. Increasing tariffs and prices for the consumed energy and heat citizens can feel on themselves. The diverse opinions of representatives of all government levels, departments and organizations converge in one thing: it is necessary to reduce the energy consumption, develop energy efficiency and energy saving measures in the country which will contribute to this. The relevance of this study is based on the lack of a mechanism to meet the social, economic, aesthetic and ecological needs of a person. Nevertheless, the problems of ecology and environmental protection are still acute and urgent. Levels of water and air pollution remain high due to outdated equipment and insufficient integration of modern technologies and waste treatment facilities. Motor transport increased the pollution level of the urban airspaces. Taking into consideration the significant growth of passenger transport, the reduction of trucks in the general traffic flows does not reduce the overall air and noise pollution in the roadside territories.
\end{abstract}

\section{Introduction}

Energy efficiency in civil engineering is a set of measures aimed at reducing the electrical and thermal energy consumed by buildings, which is needed to maintain the required parameters of energy consumption and microclimate, with the appropriate technical and economic justification for the implemented measures and ensured safety level. The purpose of implementing energy-efficient technologies is the effective (rational) use of energy resources. For the construction sector there is a great potential for reducing the expenses [1]. Use of the less energy (electricity and heat) than it was necessary before to ensure the same level of energy supply for real estate or technological processes.

Every year the housing and utility sector irrationally consumes up to $40 \%$ of energy resources. Losses of public utilities are covered by state subsidies and higher tariffs for the citizens. All this is caused by the non-closing entry doors, the sheared corridor radiators and

\footnotetext{
*Corresponding author: proflarionov@mail.ru
} 
old window frames with crack width up to $1 \mathrm{~cm}$. The implementation of energy-saving technologies will reduce the expenses by a third.

\section{Materials and methods}

The erection of energy efficient houses is advantageous where it can be done with local building materials, the costs are reduced and resource savings starts during the construction stage. Energy efficient houses are built in 42 constituent entities of the Russian Federation, mainly according to the resettlement program of citizens from dilapidated housing [2].

Currently, energy saving technologies are one of the key development trends of Russia's energy policy. Due to the fact that the country's economy is energy-intensive, the necessary measures to ensure saving of energy are:

- elimination of technological backwardness of industry sector;

- fitting out the enterprises with new energy-saving equipment;

- attraction of a sufficient amount of investments into energy saving;

- combating mismanagement in the use of energy resources.

Another promising trend intended on replacing traditional fuels in the future is the transition to energy-saving technologies within a framework of renewable energy sources. This gives not only a significant reduction of energy expenditures, but also has great environmental benefits.

At the present stage, there are three main energy saving trends:

- beneficial use (utilization) of energy losses;

- modernization of equipment in order to reduce energy losses;

- intensive energy saving.

Energy efficiency and energy saving technologies have been recently considered at the level of state and international policy. The issues of energy resources cost increase, depletion of natural resources and climate changes are discussed in detail. Those are the reasons for the tariffs and prices for consumed energy, hot water and heat to systematically rise from year to year. The opinions of representatives of all government and departments levels converge that it is necessary to reduce the energy consumption, develop measures for energy efficiency and energy saving in the country which will contribute to this [3]. 


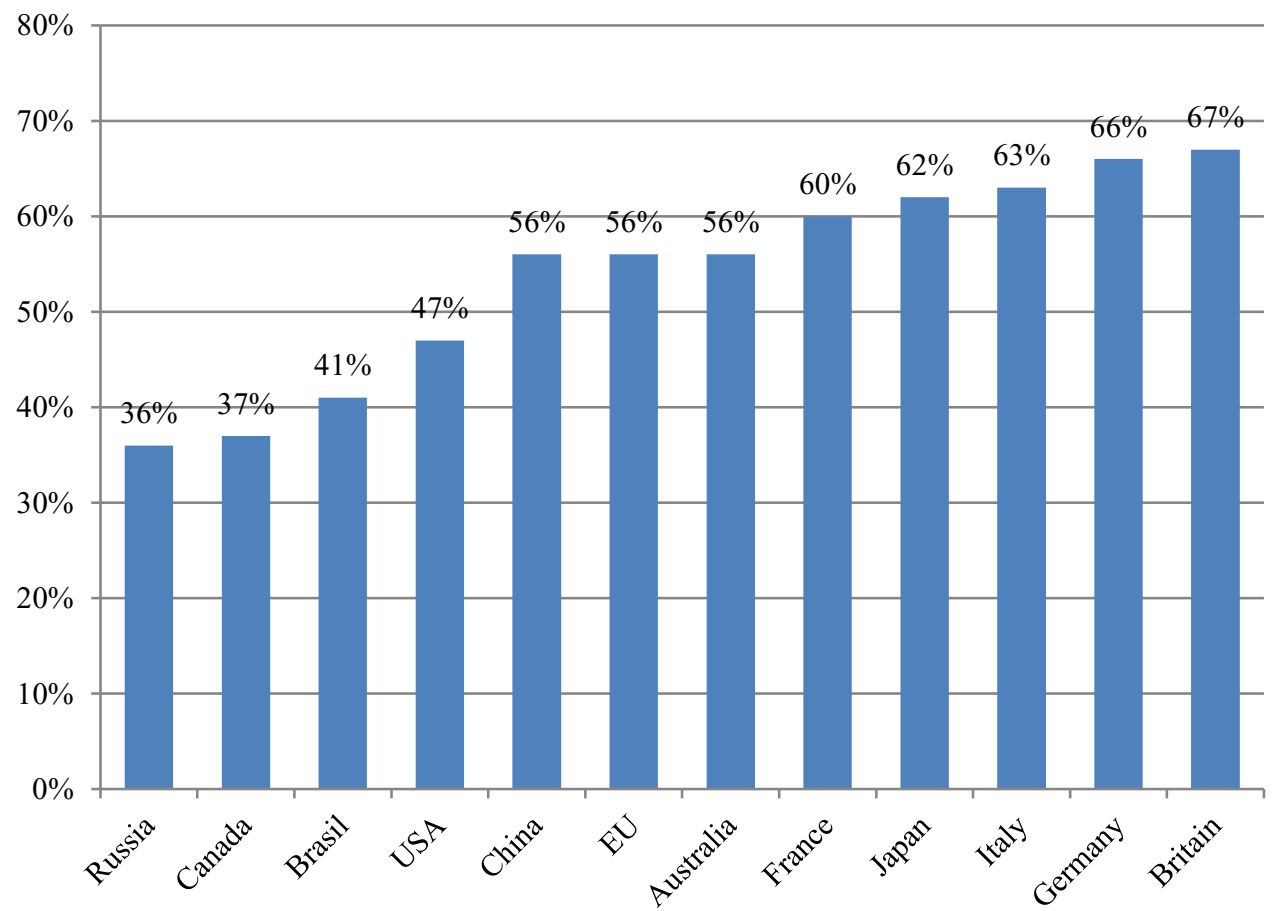

Fig. 1. Rationality of energy consumption by country.

In order to become energy efficient the house should comprise the following solutions on the construction stage.

1. Implementing modern thermal insulation of heating and hot water pipelines.

2. An individual source of heat and power supply (an individual boiler room or a source of energy cogeneration).

3. Heat pumps using the heat of the earth, the heat of the exhaust ventilation air and the heat of the waste water.

4. Solar collectors in the system of hot water supply and in the cooling system of spaces.

5. Apartment heating systems with heat meters and with individual regulation of the thermal conditions of premises.

6. System of mechanical exhaust ventilation with individual regulation and utilization of exhaust air heat.

7. Housing controllers that optimize the heat consumption for heating and ventilation of the apartments.

8. Enclosing structures with improved thermal insulation and specified values of thermal resistance.

9. Heat utilization of solar radiation in the building thermal balance on the basis of the optimal choice of translucent enclosing structures.

10. Devices, which use diffuse solar radiation in order to increase the illumination of rooms and reduce energy consumption for lighting.

11. Selecting the sun protection devices considering the orientation and seasonal irradiance of the facades.

12. Use of the return water heat from a district heating system for underfloor heating in bathrooms. 
13. Control system for heat and power supply, microclimate of premises and engineering equipment of the building based on the building mathematical model as a unified heat and power system.

In addition, the increase in the number of buildings with improved energy efficiency can be considered as a positive trend for Russia, also due to the improvement of the environmental situation as the volume of industrial emissions into the environment decreases. What measures should the managing authority take in order to save energy and improve the energy efficiency of apartment houses? Nowadays, there are certain energy efficiency classes. Energy efficiency classes of buildings A ++, A +, A, B +, B, C +, C, C-, $\mathrm{D}, \mathrm{E}$ [5] exist in Russia. According to this system it is clear that class A (the highest buildings) consume much less energy for supporting all the necessary functions to provide a normal environment in the building [4]. The amount of payment for utility services is also lower than in buldings with low energy efficiency. The classification also takes into account the resources spent on communal needs. It should be noted that other countries have successfully used this model for decades, and its principles have been taken as a basis for dividing the buildings in Russia to energy efficiency classes [5].

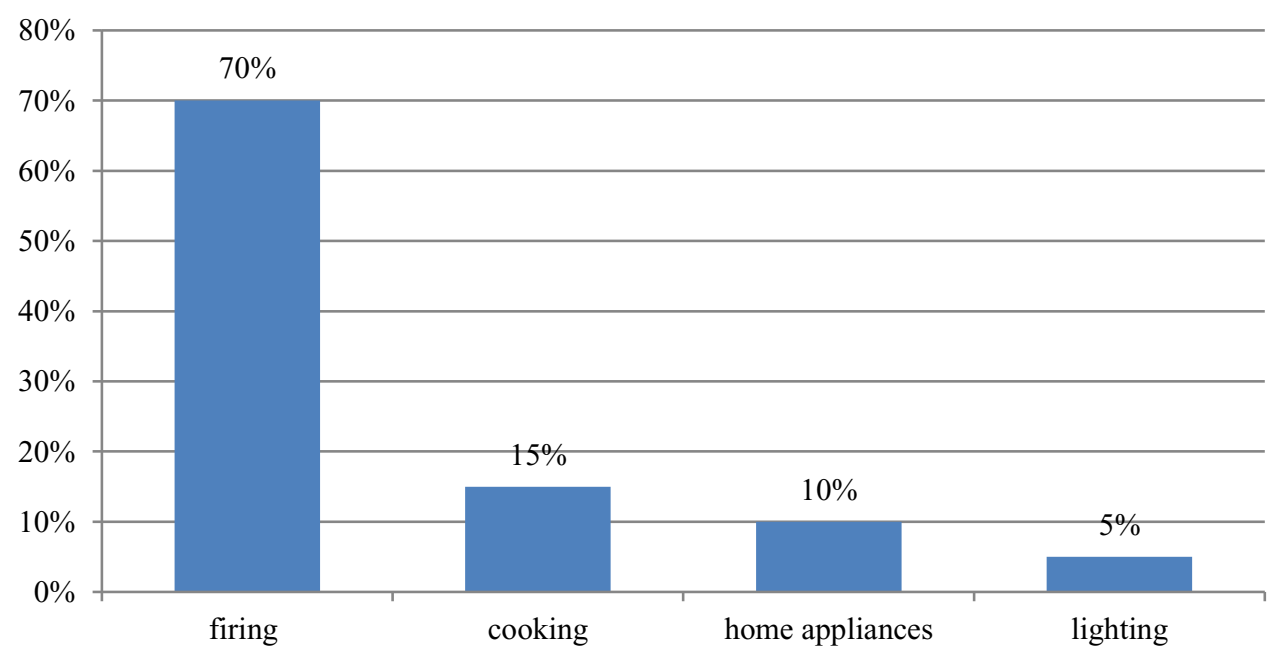

Fig. 2. Consumption of energy in household use.

The cause of large heat losses in the urban economy is the poor thermal insulation of the houses where we live. If the heat leakage in multi-storey buildings through the windows, walls, roofs, basements and ventilation will be reduced, up to $30 \%$ of the heat received from the TPP can be saved [6].

Later, when large-block construction began to dominate in the industry, the issue of heat losses also did not rise. At any rate, designers and builders did not take into account this need. Citizens, however, were concerned not with energy saving, but with drafts. With the beginning of autumn, the interior of the apartment was supplemented with a calorimeter took away from the mezzanine. By the November holidays, the people began to zealously stuff the cracks of the window frames and balcony doors with cotton wool, and paper tapes cut from newspapers were glued on top.

However, the concept of an energy efficient home includes not only the insulation of structures with heat-insulating materials, but also accounting of the utilities costs and expenditures for specific engineering solutions for the ventilation and heating systems.

Increasing the efficiency of the natural resources usage, as well as reducing the harmful effects on the environment contributes to the achievement of the main goal - to minimize the impact of buildings on people and the environment. This should be considered both at 
the construction stage (usage of local building materials) and at the exploitation stage (use of renewable energy sources).

World statistics is relentless: about $40 \%$ of the world's energy is consumed by buildings for living, and carbon dioxide emissions are about $35 \%$. There is no escaping the fact that $50 \%$ of solid household waste are urban waste.

The criteria for ecological construction are defined in the scientific literature (Figure 3).

\begin{tabular}{|c|c|}
\hline $\begin{array}{c}\text { Rational water } \\
\text { consumption }\end{array}$ & \begin{tabular}{c} 
Place of construction \\
\hline Quality materials \\
Rational energy use
\end{tabular} \\
\hline
\end{tabular}

Fig. 3. Criteria for ecological construction.

The purposes of ecological construction are as follows:

- reduction of negative impact from the construction process on people and the environment;

- introduction of new technologies;

- reducing the amount of energy consumption;

- reducing the expenditures for the erection and maintenance of buildings [7].

\section{Results}

Ecological focus does not imply only a certain type of buildings, but also a complex approach to the principles of construction and maintenance of buildings.

Let's take a closer look to the basic principles of ecological construction.

The first principle is the use of natural building materials. This principle implies the use of natural materials as well as recycled ones. It should be noted that the preference is given to local materials.

The second principle is the environmental safety. This principle is very important at all stages: construction, maintenance and demolition.

The third principle is energy efficiency. An environmentally friendly building should not consume a lot of energy (electrical, thermal etc.). Ideally, an ecological building should not be dependent on any certain type of energy.

According to the principles of ecological construction, it is possible to reduce the harmful impact at all levels of urban life, the residential cell, courtyard, housing complex, residential area (urban area) and at the city as a whole, industrial area and the territory adjacent to the city. In this case, the impact of environmental factors on the urban system is represented as an impact on a person.

Based on the above, the development of ecological construction in the post-industrial economic paradigm, represented as a result of the interaction process of its innovation platform subjects, is based on a number of following principles:

1) the principle of collective action, which postulates the need for a balanced interaction between subjects to form appropriate formal and informal standards for their interaction;

2) the connectivity principle, according to which the subjects striving to achieve a common focal goal leads to the objective forming of clusters of the maximum interactions intersection among them;

3) the principle of information asymmetry, according to which the generation of managerial influences is based on knowledge of the information obtaining methods. The 
information also can be used by subjects in order to manipulate and lobby their subjective interests.

4) the optimality principle, which presumes the interaction optimizing of the subjects based on the balance of interests with corresponding density increase in the institutional environment. In accordance with the above mentioned principles, the researchers identified the main focuses for optimizing the interaction between subjects of the innovation ecological construction platform. These are the growth of the interaction coherence and the reduction of transaction expenses caused by a certain informational asymmetry among subjects.

The effectiveness of the ecological construction development is based on the effectiveness of the process for each subject of the innovation platform, on the connectivity level and coordination of interactions between them, as well as the dynamics nature of environmental factors.

The interaction of the subjects of the innovation platform based on a balance of interests while striving for a common focal purpose contributes to the growth of the innovation network connectivity and the intensification of the processes of institutional changes. These processes increase the density of the institutional environment by increasing the number and quality of formal standards. They also increase the effectiveness of the green construction process and contribute to the formation of informal requirements for its development. Since the interaction effect of the subjects of the innovation platform is not only the sum of the subjects effects, but also leading to the achievement of the overall goal, which is the development of ecological construction, one can speak of a synergetic effect of improving the interaction between subjects.

\section{Discussion}

The innovative platform for ecological construction does not simply unite the combination of organizations accomplishing certain functions. It represents a system of interaction between the subjects based on the implementation of innovative ecological and economic standards in construction at all stages of the building's life cycle. This system is based on the principle of collective action in the institutional environment formed by a number of formal and informal standards generated by technological innovations. Throughout the interaction subjects form a network that has a single strategic goal, which is the development of ecological construction.

Institutional characteristics of subjects interaction of innovative ecological construction platform are the standards based on which certain functions (institutions) of each subject or sector of the innovation platform are realized. During the interaction of green construction subjects, formal standards are considered, which represent construction norms and requirements, environmental standards, regulatory framework for contracting and environmental legislation. In addition, informal standards representing the value assessment of the construction products quality, its environmental friendliness, intelligence, comfort and security for all subjects of innovative investment project, including end-users are considered.

\section{Conclusion}

Despite the energy efficient technologies and materials implemented in the construction of new buildings, the energy waste of the old housing stock remains the main problem. Therefore, special attention should be given to the increase of the energy efficiency of existing buildings, both now and in the long term. Despite the complex financial and 
economic situation, construction enterprises do not stop working to find reserves of energy saving, to increase the efficiency of real estate exploitation and its rational use. The existence of strict financing limits, the lack of investors and the existence of debts for the supplied energy resources cannot allow the complete realization of the energy saving potential. However, systematic work is being carried out, aimed at promising future development.

\section{References}

1. A. Bukreev, O. Vasilyeva, V. Vlasenko and E. Sizova MATEC Web of Conferences. 106, (2017)

2. I.V. Ilin, A.I. Levina, O.Yu. Iliashenko, MATEC Web of Conf., 106, 08066 (2017) DOi-10.1051/matecconf/201710608066

3. R. Bril, O.V. Kalinina, I.V. Ilin, A.S. Dubgorn, O.Yu. Iliashenko, Proc. of 20th IEEE Intern. Conf. on Soft Computing and Measurements, SCM 2017, pp 692- 693, (2017) DOi - 10.1109/SCM.2017.7970692

4. N. Harmathy, V. Murgul, Procedia Engineering, Vol.165, pp. 1845 - 1852 (2016) DOi- 10.1016/j.proeng.2016.11.932

5. A. Gorshkov, V. Murgul, Advances in Intelligent Systems and Computing, Vol. 692, pp. 577 - 591 (2018) DOi - 10.1007/978-3-319-70987-1_61

6. V. Pukhkal, V. Murgul, IOP Conference Series: Earth and Environmental Science, Vol. 90, 012211 (2017) DOi - 10.1088/1755-1315/90/1/012211

7. N. Harmathy, J. Kontra, V. Murgul, Z. Magyar, Advances in Intelligent Systems and Computing, Vol. 692, pp. 563 - 576 (2018) DOi-10.1007/978-3-319-70987-1_60 